\title{
ARTICLE
}

Chronic myeloproliferative neoplasms

\section{Blast phase myeloproliferative neoplasm: Mayo-AGIMM study of 410 patients from two separate cohorts}

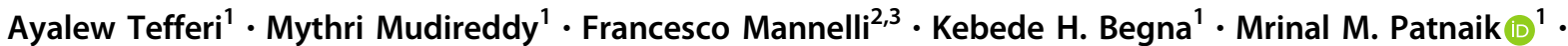 \\ Curtis A. Hanson ${ }^{1}$ - Rhett P. Ketterling ${ }^{1}$. Naseema Gangat ${ }^{1}$ - Meera Yogarajah ${ }^{4}$ - Valerio De Stefano ${ }^{2,5}$. \\ Francesco Passamonti ${ }^{2,6}$. Vittorio Rosti ${ }^{2,7}$ - Maria Chiara Finazzi ${ }^{2,8}$ - Alessandro Rambaldi ${ }^{2,8}$ - Alberto Bosi ${ }^{2,3}$. \\ Paola Guglielmelli ${ }^{2,3}$ - Animesh Pardanani ${ }^{1}$ - Alessandro M. Vannucchi ${ }^{2,3}$
}

Received: 6 November 2017 / Revised: 5 December 2017 / Accepted: 21 December 2017 / Published online: 2 February 2018

(c) The Author(s) 2018. This article is published with open access

\begin{abstract}
A total of 410 patients with blast phase myeloproliferative neoplasm (MPN-BP) were retrospectively reviewed: 248 from the Mayo Clinic and 162 from Italy. Median survival was 3.6 months, with no improvement over the last 15 years. Multivariable analysis performed on the Mayo cohort identified high risk karyotype, platelet count $<100 \times 10^{9} / \mathrm{L}$, age $>65$ years and transfusion need as independent risk factors for survival. Also in the Mayo cohort, intensive chemotherapy resulted in complete remission (CR) or CR with incomplete count recovery (CRi) rates of 35 and 24\%, respectively; treatment-specified 3-year/5-year survival rates were $32 / 10 \%$ for patients receiving allogeneic stem cell transplant (AlloSCT) $(n=24)$, 19/13\% for patients achieving CR/CRi but were not transplanted $(n=24)$, and $1 / 1 \%$ in the absence of both AlloSCT and CR/CRi $(n=200)(\mathrm{p}<$ 0.01). The survival impact of AlloSCT (HR 0.2, 95\% CI 0.1-0.3), CR/CRi without AlloSCT (HR 0.3, 95\% CI 0.2-0.5), high risk karyotype (HR 1.6, 95\% CI 1.1-2.2) and platelet count $<100 \times 10^{9} / \mathrm{L}$ (HR 1.6, 95\% CI 1.1-2.2) were confirmed to be interindependent. Similar observations were made in the Italian cohort. The current study identifies the setting for improved short-term survival in MPN-BP, but also highlights the limited value of current therapy, including AlloSCT, in securing long-term survival.
\end{abstract}

\section{Introduction}

The World Health Organization (WHO) classification system currently recognizes four variants of myeloproliferative neoplasms (MPN) associated with JAK2, CALR or MPL mutations: primary myelofibrosis (PMF), prefibrotic PMF

All authors have reviewed and approved the manuscript.

Electronic supplementary material The online version of this article (https://doi.org/10.1038/s41375-018-0019-y) contains supplementary material, which is available to authorized users.

Ayalew Tefferi

tefferi.ayalew@mayo.edu

Mayo Clinic, Rochester, MN, USA

2 AGIMM (AIRC-Gruppo Italiano Malattie Mieloproliferative: Rome, Varese, Pavia, Bergamo, Florence, Italy

3 CRIMM, Center for Research and Innovation of Myeloproliferative Neoplasms, University of Florence, AOU Careggi, Florence, Italy

4 Brody School of Medicine, East Carolina University,
(pre-PMF), essential thrombocythemia (ET) and polycythemia vera (PV); [1] in addition, 5-30\% patients with ET or PV experience fibrotic progression of their disease over time, referred to as post-ET and post-PV myelofibrosis, respectively [2]. All of these MPN variants might evolve into blast phase disease (MPN-BP), operationally defined by the presence of $\geq 20 \%$ blasts in the blood or bone marrow [1]. The risk of leukemic transformation in MPN depends on the MPN variant and is highest in PMF, with an incidence of $10-20 \%$, in the first 10 years of the disease, lower in PV, with estimated risk of $3 \%$ at 10 years and $8 \%$ at 20 years, and lowest in ET with less than $1 \%$ risk in the first

Greenville, NC, USA

5 Institute of Hematology, Catholic University, Roma, Italy

6 Department of Medicine and Surgery, University of Insubria, ASST Settelaghi, Ospedale di Circolo, Varese, Italy

7 Center for the Study of Myelofibrosis, Laboratory of Biochemistry, Biotechnology and Advanced Diagnosis, Foundation IRCCS Policlinico San Matteo, Pavia, Italy

8 Department of Oncology and Hemato-oncology University of Milan and Ospedale Papa Giovanni XXIII, Bergamo, Italy 
decade of disease [3-6]. Leukemic transformation rates do not appear to be different between PMF and fibrotic phases of PV or ET and the latter can transform directly into MPNBP without going through a fibrotic disease phase [7-9].

Reported risk factors for leukemic transformation in PMF include unfavorable karyotype, especially monosomal karyotype, thrombocytopenia, excess circulating blasts, marked leukocytosis, transfusion-requiring anemia, older age and increased levels of serum interleukin- 8 and $C$ reactive protein; [10-15] also in play are both driver and other mutations, where triple-negative driver mutational status and presence of ASXL1, SRSF2, IDH1/2, RUNX1, $C E B P A$ or $S H 2 B 3$ mutations have been associated with higher and $C A L R$ type 1-like mutation with lower risk of leukemic transformation [3, 16-20]. Risk factors reported for leukemic transformation in PV include leukocytosis, older age, abnormal karyotype, presence of $S R S F 2$ or $I D H 2$ mutations and treatment with radiophosphorous, chlorambucil or pipobroman [6, 21-25]. In ET, accurate morphologic diagnosis is critical in assessing leukemia risk, because of the need to distinguish between strictly WHOdefined ET and pre-PMF; [4] reported risk factors for leukemic transformation have included anemia, extreme thrombocytosis, older age, leukocytosis, and presence of TP53 or EZH2 mutations [4, 25-30].

Prognosis in MPN-BP is extremely poor; in an earlier study of 91 patients, we had reported a median survival of less than 3 months for patients receiving supportive care only and approximately 6 months for those receiving acute myeloid leukemia (AML)-like induction chemotherapy [7]. The dismal prognosis of MPN-BP has also been highlighted by other more recent studies where specific treatment did not appear to influence either progression-free or overall survival whereas patients receiving allogeneic stem cell transplant (AlloSCT) in complete remission (CR) might have achieved significantly longer survival [31]. The possibility of longer survival with AML-like induction chemotherapy and AlloSCT has also been reported by others, although inconsistently [31]. In the current study, we retrospectively reviewed consecutive cases of MPN-BP from the institutional databases of the Mayo Clinic, Rochester, MN, USA and the AIRC-Gruppo Italiano Malattie Mieloproliferative (AGIMM), with the intent to examine (i) recent survival trends, (ii) treatment outcome, including response rates to treatments received for blast phase disease and (iii) risk factors for survival, including the impact of chemotherapy and AlloSCT.

\section{Methods}

The current study constitutes a retrospective review of consecutive cases of MPN-BP, where diagnoses of leukemic transformation and the antecedent MPN were confirmed by both clinical and bone marrow examinations, in line with the WHO criteria [1]. Study patients were recruited from institutional databases of the Mayo Clinic, Rochester, MN, USA and the AGIMM, after approval from the respective institutional review boards. The two patient cohorts were analyzed separately and not combined. The Mayo Clinic cohort constituted the central core and the Italian cohort was used to confirm some of the important observations from the Mayo cohort. Both patient cohorts also examined survival trends over the last 15 years whereas an even earlier period was also considered in the Mayo cohort analysis, based on availability of information on patients diagnosed earlier. Estimates for chemotherapyinduced complete remission (CR) and CR with incomplete blood count recovery (CRi) rates were obtained for both patient cohorts. However, a more detailed analysis of risk factors and treatment-specified outcome data was performed, mostly on the Mayo patient cohort, based on ease of access to centralized data.

Clinical and laboratory data, including cytogenetic information, were collected from patients at the time of leukemic transformation. Cytogenetic analysis and reporting was done according to the International System for Human Cytogenetic Nomenclature criteria. For the purposes of the current study, and based on previously established prognostic relevance [32], the following cytogenetic abnormalities were identified as being "high risk": monosomal karyotype and single or multiple abnormalities of -7 , $\operatorname{inv}(3)(\mathrm{q} 21.3 \mathrm{q} 26.2) / \mathrm{t}(3 ; 3)(\mathrm{q} 21.3 ; \mathrm{q} 26.2)$ and $\mathrm{i}(17)(\mathrm{q} 10)$. Survival was calculated from time of leukemic transformation, commensurate with time of cytogenetic analysis, and collection of clinical and laboratory parameters examined for impact on survival. Standard statistical methods were used to determine significance of differences among groups in the distribution of continuous or nominal variables. Overall survival data were prepared by the Kaplan-Meier method and compared by the log-rank test. Cox proportional hazard regression model was applied for multivariable analysis. $P$-value $<0.05$ was considered significant. The Stat View (SAS Institute, Cary, NC, USA) statistical package was used for all calculations.

\section{Results}

\section{Patient characteristics at time of leukemic transformation}

The Mayo Clinic cohort included 248 consecutive patients (median age 67 years; $65 \%$ males) with MPN-BP, including $118(48 \%)$ post-PMF and 130 (52\%) post-PV/ET MPN-BP; among the latter, 60 patients had post-PV (32 without 
Table 1 Clinical and laboratory characteristics of 248 patients with blast phase myeloproliferative neoplasms at the time of leukemic transformation

\begin{tabular}{|c|c|c|c|c|}
\hline Variables & $\begin{array}{l}\text { All patients } \\
(n=248)\end{array}$ & $\begin{array}{l}\text { Post-PMF AML } \\
(n=118)\end{array}$ & $\begin{array}{l}\text { Post-PV/ET AML }{ }^{\mathrm{a}} \\
(n=130)\end{array}$ & $P$-value \\
\hline Age in years; median (range) & $67(40-90)$ & $67(40-87)$ & $68(42-90)$ & 0.3 \\
\hline Age $>65$ years; $n(\%)$ & $140(56)$ & $63(53)$ & $77(59)$ & 0.4 \\
\hline Sex (male); $n(\%)$ & $161(65)$ & $84(71)$ & $77(59)$ & 0.04 \\
\hline Transfusion dependent; $n(\%)$ "N" evaluable $=233$ & $80(34)$ & $51(46)$ & $29(24)$ & 0.0004 \\
\hline Hemoglobin, g/dl; median (range) "N" evaluable $=217$ & $9.3(0.7-18.1)$ & $9(6.1-13.7)$ & $9.5(0.7-18.1)$ & 0.05 \\
\hline Platelets x $10^{9} / \mathrm{L}$; median (range) "N" evaluable $=216$ & $78(3-2051)$ & $69(4-670)$ & $100(3-2051)$ & 0.004 \\
\hline Platelets $<100 \times 10^{9} / \mathrm{L} ; n(\%)$ "N" evaluable $=216$ & $126(58)$ & $68(69)$ & $58(50)$ & 0.004 \\
\hline Leukocytes x $10^{9} / \mathrm{L}$; median (range) "N" evaluable $=218$ & $15.9(0.4-600)$ & $22.2(0.5-154)$ & $14.3(0.4-600)$ & 0.09 \\
\hline Leukocytes $>25 \times 10^{9} / \mathrm{L} ; n(\%)$ "N" evaluable $=218$ & $81(37)$ & $42(42)$ & $39(33)$ & 0.2 \\
\hline Circulating blasts $\%$; median (range) "N" evaluable $=215$ & $26(0-99)$ & $29(1-99)$ & $22(0-89)$ & 0.005 \\
\hline Circulating blasts $\geq 20 \% ; n(\%)$ "N" evaluable $=215$ & $152(71)$ & 77 (77) & $75(65)$ & 0.06 \\
\hline Bone marrow blasts $\%$; median (range) "N" evaluable $=180$ & $33(1-97)$ & $36(2-97)$ & $30(1-91)$ & 0.09 \\
\hline Bone marrow blasts $\geq 20 \% ; n(\%)$ "N" evaluable $=180$ & $156(87)$ & $64(86)$ & $92(87)$ & 0.9 \\
\hline ANC, x $10^{9} / \mathrm{L} ;$ median (range) "N" evaluable $=207$ & $4.9(0-68.9)$ & $5.4(0-56.1)$ & $4.3(0.1-68.9)$ & 0.98 \\
\hline AMC, x $10^{9} / \mathrm{L}$; median (range) "N" evaluable $=204$ & $0.7(0-36.2)$ & $0.7(0-25.3)$ & $0.7(0-36.2)$ & 0.45 \\
\hline Karyotype "N" evaluable $=172$ Normal; $n(\%)$ Abnormal; $n(\%)$ & $32(19) 140(81)$ & $18(23) 59(77)$ & $14(15) 81(85)$ & 0.3 \\
\hline$J A K 2$ mutated; $n(\%)$ "N" evaluable $=144$ & $98(68)$ & $35(60)$ & $63(73)$ & 0.1 \\
\hline Allogeneic stem cell transplant; $n(\%)$ & $24(11)$ & $9(8)$ & $15(13)$ & 0.3 \\
\hline Follow up in months; median (range) & $3.6(0-122)$ & $3.3(0-72)$ & $4(0-122)$ & 0.7 \\
\hline Deaths; $n(\%)$ & $239(96)$ & $115(97)$ & $124(95)$ & 0.4 \\
\hline
\end{tabular}

$A M L$ acute myeloid leukemia, $P M F$ primary myelofibrosis, $P V$ polycythemia vera, $E T$ essential thrombocythemia, $A N C$ absolute neutrophil count, $A M C$ absolute monocyte count, JAK2 Janus kinase 2

${ }^{a}$ Post PV AML patients, $N=60$

Post PV AML without myelofibrosis phase, $N=32$

Post PV AML with myelofibrosis phase, $N=28$

Post ET AML patients, $N=70$

Post ET AML without myelofibrosis phase, $N=39$

Post ET AML with myelofibrosis phase, $N=31$

documented MF phase) and 70 post-ET (39 without documented MF phase) MPN-BP (Table 1). Bone marrow examination morphology reports included 103 (42\%) patients with acute myeloid leukemia, not otherwise specified (AML-NOS), 64 (26\%) with AML with myelodysplasia-related changes, 17 (7\%) with AML-NOSM7, 14 (6\%) with AML-NOS-M2, 12 (5\%) with AML-NOS-M5, 10 (4\%) with AML-NOS-M4, 8 (3\%) with AML-NOS-M0, 6 (2\%) with AML-NOS-M1, 3 (1\%) with AML-NOS-M6 and $3(1 \%)$ with AML with recurrent favorable cytogenetic abnormalities; $8(3 \%)$ patients presented with myeloid sarcoma. Among all evaluable cases, at the time of leukemic transformation, 34\% displayed red cell transfusion need, $58 \%$ platelet count $<100 \times 10(9) / 1,37 \%$ leukocyte count $>25 \times 10(9) / 1,71 \%$ circulating blasts $\geq$ $20 \%, 87 \%$ bone marrow blasts $\geq 20$ and $68 \%$ JAK2V617F mutation (Table 1). Cytogenetic information was available in 172 cases, out of which $140(81 \%)$ were reported out as abnormal and 19\% $(n=32)$ normal; among the 140 abnormal cases, 56 (40\%) were labelled as "high risk", based on the presence of monosomal karyotype or monosomy $7(n=46)$ or single or multiple abnormalities including $\operatorname{inv}(3)(\mathrm{q} 21.3 \mathrm{q} 26.2) / \mathrm{t}(3 ; 3)(\mathrm{q} 21.3 ; \mathrm{q} 26.2)(n=5)$, or $\mathrm{i}(17)$ (q10) $(n=5)$.

Compared to post-PMF MPN-BP, post-PV/ET MPN-BP cases displayed female preponderance $(p=0.04)$, lower percentage of red cell transfusion need $(p=0.0004)$, higher platelet count $(p=0.004)$ and lower circulating blast percentage $(p=0.005)$ (Table 1). Cytogenetic profile and prevalence of $J A K 2 \mathrm{~V} 617 \mathrm{~F}$ mutation were similar between post-PMF and post-PV/ET MPN-BP (Table 1).

The AGIMM cohort consisted of 162 consecutive patients (median age 69 years; $57 \%$ males) with MPN-BP, including 70 (43\%) post-PMF MPN-BP and $92(57 \%)$ postPV/ET MPN-BP; among the latter, 37 patients had post-PV (14 without documented MF phase) and 52 post-ET (30 
a

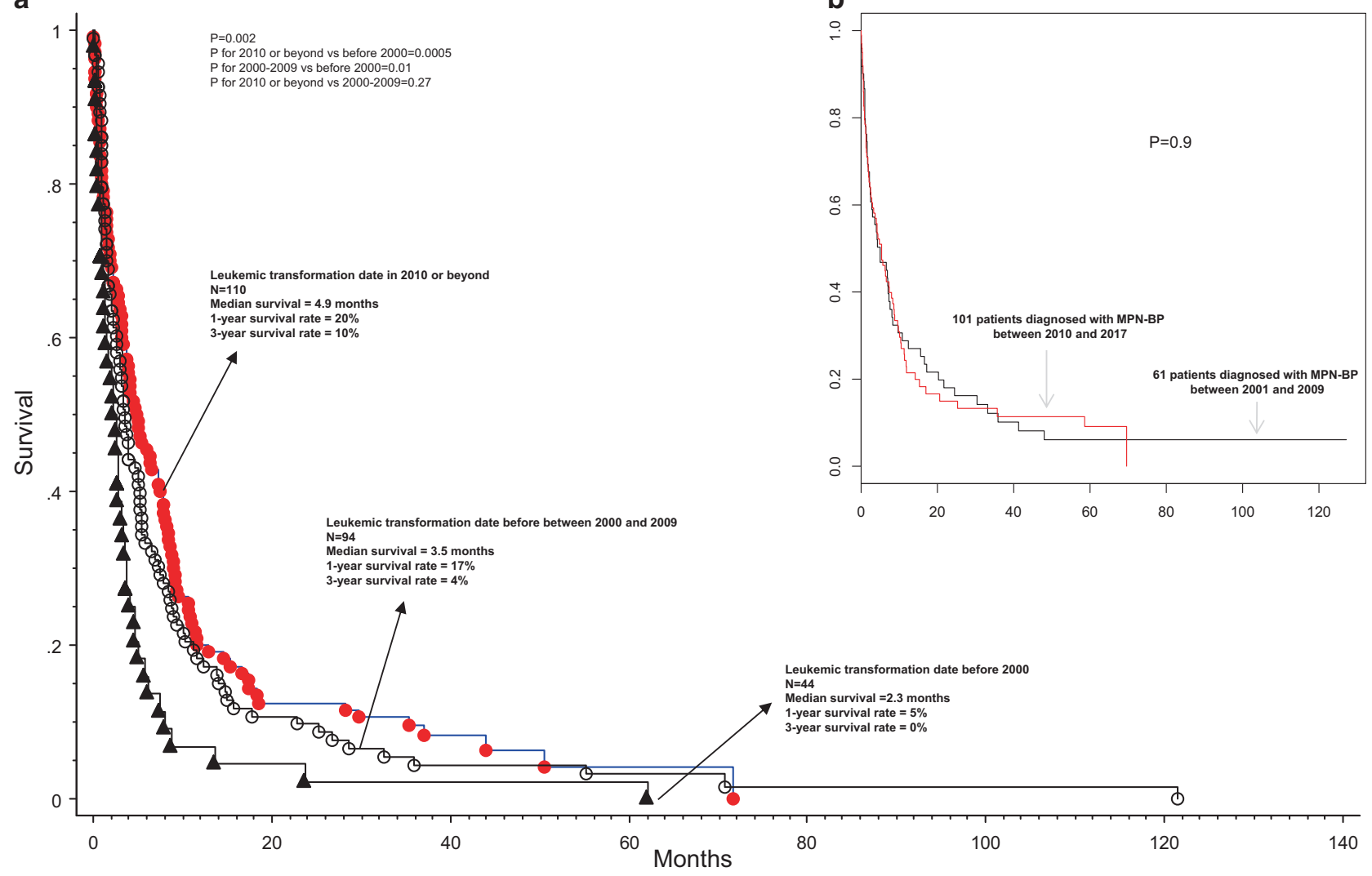

Fig. 1 a Survival data on 248 Mayo Clinic patients with blast-phase myeloproliferative neoplasm, stratified by year of diagnosis; b Survival data on 162 Italian patients with blast-phase myeloproliferative neoplasm, stratified by year of diagnosis

without documented MF phase) MPN-BP; antecedent MPN was not verified in 3 cases. Among all evaluable cases in the AGIMM cohort, at the time of leukemic transformation, $37 \%$ displayed red cell transfusion need, $55 \%$ platelet count $<100 \times 10(9) / \mathrm{L}, \quad 36 \%$ leukocyte count $>25 \times 10(9) / \mathrm{L}$, $61 \%$ circulating blasts $\geq 20 \%, 97 \%$ bone marrow blasts $\geq$ $20 \%, 61 \%$ abnormal karyotype and $61 \%$ JAK2V617F mutation.

\section{Survival trends over time}

In the Mayo Clinic cohort, after a median follow-up of 3.6 months (range 0-122), 239 (96.4\%) deaths were recorded. Median survival was 3.6 months with 1, 3, and 5year survival rates of 17,6 , and $4 \%$, respectively; survival trends appeared significantly better for patients diagnosed in the year 2000 and afterwords, but with no additional improvement in the last 15 years (Fig. 1a); median survival of patients diagnosed with MPN-BP prior to the year 2000 vs in the years 2000-2009 vs in 2010 and afterwards was 2.3 (1-year and 3-year survival rates of 5 and $0 \%$ ) vs 3.5 (1year and 3-year survival rates of 17 and 4\%) vs 4.9 months (1-year and 3-year survival rates of 20 and 10\%), respectively $(p=0.002)$; survival was similar for the diagnosis period of 2010 and afterwards vs 2000-2009 ( $p=0.27$; Fig. 1a). The AGIMM cohort was followed for a median of 3 months (range 0-127) and median survival was 3.6 months with 1 and 3-year survival rates of 25 and $11 \%$, respectively; as was the case with the Mayo cohort, survival trends were not significantly different according to year of diagnosis, for patients diagnosed after the year 2000 ( $p=$ 0.9 ; Fig. 1b).

\section{Overall management strategies and predictors of treatment response}

Treatment records were reviewed in detail for the 248 Mayo Clinic patients; 121 (49\%) were managed with supportive care only, including the use of hydroxyurea for control of leukocytosis, $79(32 \%)$ were treated with a variety of chemotherapeutic agents that were considered to be more intensive than hydroxyurea, but failed to show a response, $24(10 \%)$ received AlloSCT and 24 (10\%) achieved chemotherapy-induced $\mathrm{CR}$ or $\mathrm{CR}$ with incomplete blood count recovery (CRi) but were not subsequently transplanted (Table 2); among the 24 transplanted patients, 16 were in CR/CRi at the time of AlloSCT while 8 received AlloSCT either directly without pre-transplant induction 
Table 2 Clinical and laboratory characteristics of 248 patients with blast phase myeloproliferative neoplasms at the time of leukemic transformation, stratified by their overall management and response categories

\begin{tabular}{|c|c|c|c|c|c|c|c|}
\hline Variables & $\begin{array}{l}\text { All patients } \\
(n=248)\end{array}$ & $\begin{array}{l}\text { Patients not } \\
\text { transplanted and } \\
\text { received } \\
\text { supportive care } \\
\text { only }(n=121)\end{array}$ & $\begin{array}{l}\text { Patients not } \\
\text { transplanted but } \\
\text { received } \\
\text { chemotherapy } \\
\text { with no response } \\
(n=79)\end{array}$ & $\begin{array}{l}\text { Patients not } \\
\text { transplanted but } \\
\text { achieved CR/ } \\
\text { CRi with } \\
\text { chemotherapy } \\
(n=24)\end{array}$ & $\begin{array}{l}\text { Patients } \\
\text { transplanted } \\
\text { directly or after } \\
\text { failing } \\
\text { chemotherapy } \\
(n=8)\end{array}$ & $\begin{array}{l}\text { Patients } \\
\text { transplanted in } \\
\text { CR or CRi with } \\
\text { pre-transplant } \\
\text { chemotherapy } \\
(n=16)\end{array}$ & $P$-value \\
\hline $\begin{array}{l}\text { Age in years; median } \\
\text { (range) }\end{array}$ & $67(40-90)$ & $70(40-90)$ & $66(46-90)$ & $63(45-82)$ & $57(44-68)$ & $56(42-70)$ & $<0.0001$ \\
\hline Age $>65$ years; $n(\%)$ & $140(56)$ & $87(72)$ & $42(53)$ & $9(38)$ & $1(13)$ & $1(6)$ & $<0.0001$ \\
\hline Sex (male); $n(\%)$ & $161(65)$ & $80(66)$ & $52(66)$ & $13(54)$ & $6(75)$ & $10(63)$ & 0.8 \\
\hline $\begin{array}{l}\text { Transfusion dependent; } n \\
(\%) \text { "N" evaluable }=233\end{array}$ & $80(34)$ & $41(38)$ & $31(39)$ & $4(17)$ & $2(29)$ & $2(13)$ & 0.08 \\
\hline $\begin{array}{l}\text { Hemoglobin, g/dl; median } \\
\text { (range) "N" evaluable }=217\end{array}$ & $9.3(0.7-18.1)$ & $9.4(5.8-14.1)$ & $8.9(0.7-14.5)$ & $9.5(6.3-15.8)$ & $8.7(7.9-14.1)$ & $9.6(6.9-18.1)$ & 0.7 \\
\hline $\begin{array}{l}\text { Platelets x } 10^{9} / \mathrm{L} \text {; median } \\
\text { (range) "N" evaluable }=216\end{array}$ & $78(3-2051)$ & $77(3-2051)$ & $80(6-691)$ & $109(11-1246)$ & $73(43-1126)$ & $67(15-412)$ & 0.9 \\
\hline $\begin{array}{l}\text { Platelets }<100 \times 10^{9} / \mathrm{L} ; n \\
(\%) \text { "N" evaluable }=216\end{array}$ & $126(58)$ & $62(61)$ & $41(59)$ & $11(48)$ & $3(60)$ & $9(56)$ & 0.9 \\
\hline $\begin{array}{l}\text { Leukocytes x } 10^{9} / \mathrm{L} \text {; median } \\
\text { (range) "N" evaluable }=218\end{array}$ & $\begin{array}{l}15.9 \\
(0.4-600)\end{array}$ & $15.5(0.5-145.5)$ & $22.3(0.6-151.1)$ & $14.6(0.4-600)$ & $55.1(2.1-154.1)$ & $5.8(1.6-56.8)$ & 0.1 \\
\hline $\begin{array}{l}\text { Leukocytes }>25 \times 10^{9} / \mathrm{L} ; n \\
(\%) \text { "N" evaluable }=218\end{array}$ & $81(37)$ & $37(36)$ & $30(42)$ & $8(35)$ & $3(60)$ & $3(19)$ & 0.4 \\
\hline $\begin{array}{l}\text { Circulating blasts \%; } \\
\text { median (range) "N" } \\
\text { evaluable }=215\end{array}$ & $26(0-99)$ & $27(0-88)$ & $26(0-99)$ & $31(0-76)$ & $22(10-89)$ & $22(10-76)$ & 0.9 \\
\hline $\begin{array}{l}\text { Circulating blasts } \geq 20 \% ; n \\
(\%) \text { "N" evaluable }=215\end{array}$ & $152(71)$ & $74(73)$ & $49(69)$ & $15(68)$ & $3(60)$ & $11(69)$ & 0.9 \\
\hline $\begin{array}{l}\text { Bone marrow blasts } \% ; \\
\text { median (range) "N" } \\
\text { evaluable }=180\end{array}$ & $33(1-97)$ & $34(3-95)$ & $30(1-97)$ & $47(5-92)$ & $29(8-58)$ & $32(8-79)$ & 0.3 \\
\hline $\begin{array}{l}\text { Bone marrow blasts } \geq 20 \% \\
n(\%) \text { "N" evaluable }=180\end{array}$ & $156(87)$ & $69(90)$ & $53(84)$ & $20(91)$ & $3(75)$ & $11(79)$ & 0.6 \\
\hline $\begin{array}{l}\text { Karyotype "N" evaluable = } \\
172 \text { Normal; } n(\%) \\
\text { Abnormal; } n(\%)\end{array}$ & $\begin{array}{l}32(19) 140 \\
(81)\end{array}$ & 9 (13) 59 (87) & 15 (25) 46 (75) & 3 (14) 19 (86) & $2(40) 3(60)$ & 3 (19) 13 (81) & 0.3 \\
\hline $\begin{array}{l}J A K 2 \text { mutated; } n(\%) \text { "N" } \\
\text { evaluable }=144\end{array}$ & $98(68)$ & $36(71)$ & $37(67)$ & $12(75)$ & $4(57)$ & $9(60)$ & 0.8 \\
\hline $\begin{array}{l}\text { Allogeneic stem cell } \\
\text { transplant; } n(\%) \text { "N" } \\
\text { evaluable }=228\end{array}$ & $24(11)$ & $0(0)$ & $0(0)$ & $0(0)$ & $8(100)$ & $16(100)$ & $<0.0001$ \\
\hline $\begin{array}{l}\text { Follow up in months; } \\
\text { median (range) }\end{array}$ & $3.6(0-122)$ & $1.6(0-59.9)$ & $4.0(0.2-70.7)$ & $8.7(1.7-71.6)$ & $25.8(7.9-122)$ & $22.6(7.8-55)$ & $<0.0001$ \\
\hline Deaths; $n(\%)$ & $239(96)$ & $119(98)$ & 79 (100) & $21(88)$ & $7(88)$ & $13(81)$ & 0.0002 \\
\hline
\end{tabular}

$A N C$ absolute neutrophil count, $A M C$ absolute monocyte count, JAK2 Janus kinase 2, CR complete remission, $C R i$ CR with incomplete blood count recovery

chemotherapy or failed to achieve CR/CRi before transplant (Table 2). Comparison of the baseline clinical characteristics, among the different treatment and response categories, revealed significant differences, only in age distribution (Table 2).

A total of 125 Mayo Clinic patients received chemotherapy that was considered to be more intensive than hydroxyurea; 69 were treated with AML-like induction chemotherapy, of whom 66 were evaluable for response, 26 with HMA and 30 with other drugs, including investigational agents. The AML-like induction chemotherapy in the 66 evaluable for response patients included idarubicin/ cytarabine-based " $7+3$ " regimen in 40 patients, daunorubicin/cytarabine-based " $7+3$ " regimen in 13 patients, "cytarabine + itoxantrone + etoposide" in 4 patients, "daunorubicin + cytarabine + nilotinib" in 2 patients, 
Table 3 Univariate and multivariable analysis of survival in 248 patients with blast phase myeloproliferative neoplasms; all variables were collected at time of leukemic transformation

\begin{tabular}{|c|c|c|c|c|c|c|}
\hline \multirow[t]{2}{*}{ Variables } & \multicolumn{3}{|c|}{ Univariate analysis } & \multicolumn{3}{|c|}{ Multivariable analysis } \\
\hline & $\begin{array}{l}\text { Hazard } \\
\text { ratio }\end{array}$ & $\begin{array}{l}95 \% \text { confidence } \\
\text { interval }\end{array}$ & $P$-value & $\begin{array}{l}\text { Hazard } \\
\text { ratio }\end{array}$ & $\begin{array}{l}95 \% \text { confidence } \\
\text { interval }\end{array}$ & $P$-value \\
\hline Age in years & & & $<0.001$ & & & \\
\hline Age $>65$ years & 1.5 & $1.1-1.9$ & 0.003 & 1.6 & $1.2-2.2$ & 0.004 \\
\hline Sex (male) & 1.1 & $0.8-1.4$ & 0.5 & & & \\
\hline MPN-MPN-BP interval ${ }^{\mathrm{a}}$ & & & 0.11 & & & \\
\hline Transfusion dependent "N" evaluable $=233$ & 1.6 & $1.2-2.1$ & 0.002 & 1.6 & $1.1-2.2$ & 0.01 \\
\hline Hemoglobin, g/dl "N" evaluable $=217$ & & & 0.1 & & & \\
\hline Platelets $\times 10^{9} / \mathrm{L}$ "N" evaluable $=216$ & & & 0.01 & & & \\
\hline Platelets $<100 \times 10^{9} / \mathrm{L}$ "N" evaluable $=216$ & 1.5 & $1.1-2.0$ & 0.004 & 1.5 & $1.1-2.1$ & 0.02 \\
\hline Leukocytes $\times 10^{9} / \mathrm{L}$ "N" evaluable $=218$ & & & 0.3 & & & \\
\hline Leukocytes $>25 \times 10^{9} / \mathrm{L}$ "N" evaluable $=218$ & 1.1 & $0.8-1.5$ & 0.5 & & & \\
\hline Circulating blast $\%$ "N" evaluable $=215$ & & & 0.8 & & & \\
\hline Circulating blasts $\geq 20 \%$ "N" evaluable $=215$ & 0.9 & $0.7-1.3$ & 0.7 & & & \\
\hline Bone marrow blast $\%$ "N" evaluable $=180$ & & & 0.4 & & & \\
\hline Bone marrow blasts $\geq 20 \%$ "N" evaluable $=180$ & 1.4 & $0.9-2.3$ & 0.1 & & & \\
\hline WHO morphologic category ${ }^{\mathrm{b}}$ & & & 0.06 & & & \\
\hline \multicolumn{7}{|l|}{ Karyotype "N" evaluable $=172$} \\
\hline Abnormal $(n=140 ; 81 \%)$ & 1.5 & $1.0-2.3$ & 0.046 & 1.8 & $1.3-2.6$ & 0.001 \\
\hline "High risk" karyotype ${ }^{c}(n=83 ; 59 \%)$ & 1.7 & $1.2-2.4$ & 0.002 & & & \\
\hline$J A K 2$-mutated "N" evaluable $=144$ & 1.1 & $0.7-1.6$ & 0.6 & & & \\
\hline \multicolumn{7}{|l|}{ MPN-BP variants } \\
\hline Post-PMF MPN-BP & 1.4 & $0.99-1.9$ & 0.06 & & & \\
\hline Post-ET MPN-BP & 1.4 & $1.0-2.1$ & 0.04 & & & \\
\hline Post-PV MPN-BP & ref & ref & ref & & & \\
\hline
\end{tabular}

$M P N-B P$ blast phase myeloproliferative neoplasm, $P M F$ primary myelofibrosis, JAK2 Janus kinase 2, $P V$ polycythemia vera, $E T$ essential thrombocythemia, $W H O$ world health organization

${ }^{a}$ Interval between initial diagnosis of MPN and leukemic transformation

${ }^{\mathrm{b}}$ Considering morphologic categories cited in at least 10 patients

${ }^{\mathrm{c}}$ High risk karyotype included monosomal karyotype, monosomy 7 or single or multiple abnormalities including inv(3)(q21.3q26.2)/t(3;3)(q21.3; q26.2)/i(17)(q10)

"daunorubicin + cytarabine + etoposide" in 2 patients, cytarabine only in 2 patients, "daunorubicin + cytarabine + zosquidar" in 1 patient, "fludarabine + cytarabine + G-CSF + idarubicin" in 1 patient and "fludarabine + cytarabine + mitoxantrone" in 1 patient.

The respective $\mathrm{CR}$ rates for $\mathrm{AML}$-like induction chemotherapy, HMA and other investigational drugs were 35, 4 , and $3 \%$; an additional $24 \%$ of patients who received AML-like induction chemotherapy achieved CRi, which was not observed in patients treated with HMA. In other words, the likelihood of obtaining CR/CRi was $59 \%$ following AML-like induction chemotherapy vs $<5 \%$ with HMA or other agents. Additional analysis of the 66 patients treated with AML-like induction chemotherapy and were evaluable for response revealed no significant associations between the achievement of $\mathrm{CR}, \mathrm{CRi}$ or no response with any other clinical or laboratory parameter, including age $(p=0.09)$, interval between MPN and MPN-BP diagnosis $(p=0.3)$, leukocyte count $(p=0.6)$, platelet count $(p=0.11)$, peripheral blood blast percentage $(p=0.77)$, bone marrow blast percentage $(p=0.28)$, presence or absence of high risk karyotype $(p=0.98)$, presence or absence of abnormal karyotype $(p=0.72)$, presence or absence of a JAK2 mutation $(p=0.15)$, antecedent MPN type $(p=0.26)$ or WHO morphological category $(p=0.37)$.

In the AGIMM patient cohort of 162 patients, 51 were reported to have received AlloSCT $(n=25)$ or intensive induction chemotherapy without AlloSCT $(n=26)$; a total of 48 patients received intensive induction chemotherapy that resulted in CR rate of $27.1 \%$ and CRi rate of $8.3 \%$. AlloSCT in the Mayo cohort was reported in 24 


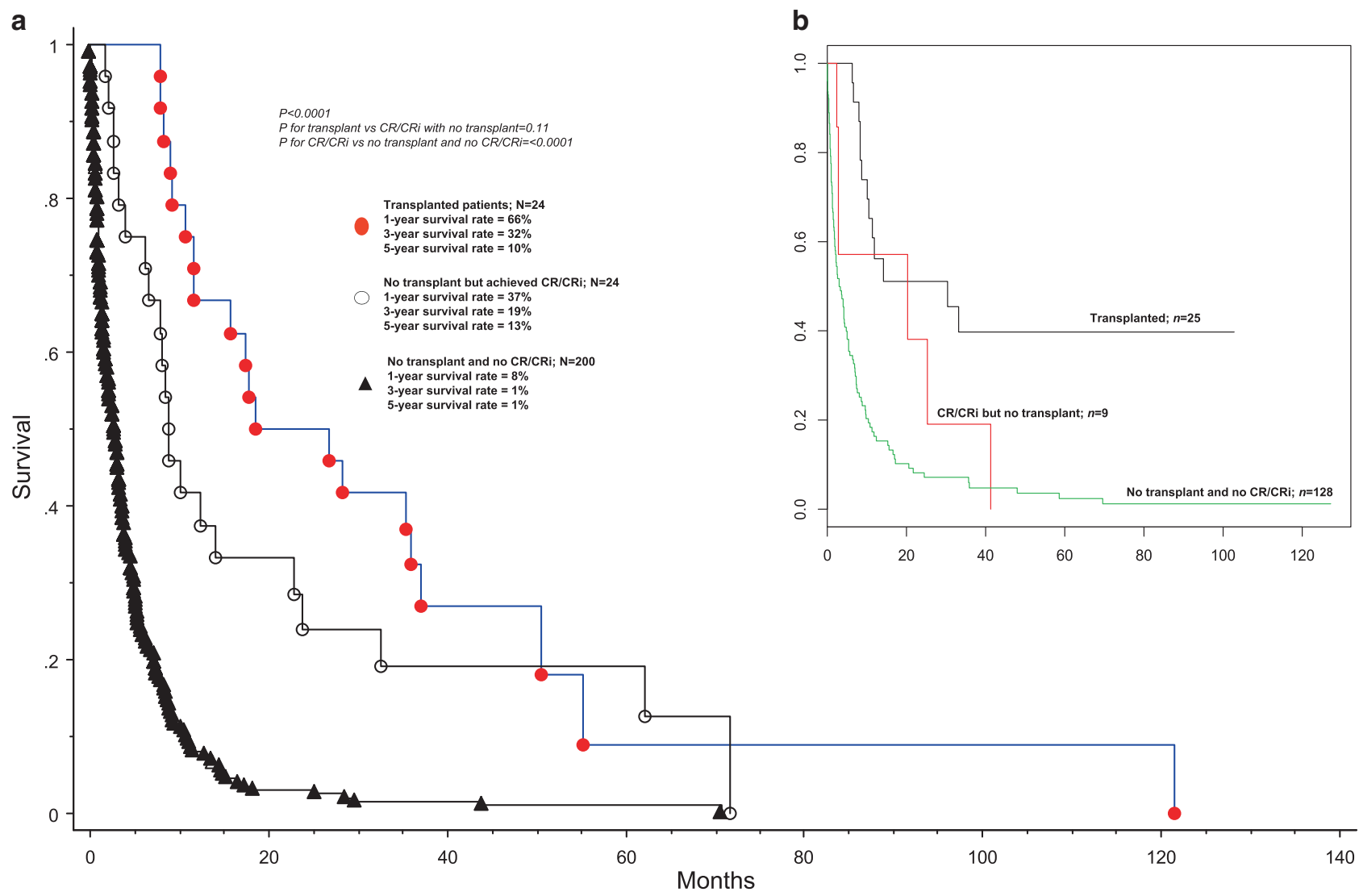

Fig. 2 a Survival data on 248 Mayo Clinic patients with blast-phase myeloproliferative neoplasm, stratified by specific treatment strategies; b Survival data on 162 Italian patients with blast-phase myeloproliferative neoplasm, stratified by treatment received

patients, of whom 16 had received AML-like induction chemotherapy and were transplanted in either CR $(n=10)$ or CRi $(n=6)$ while the other 8 were transplanted either directly without pre-transplant chemotherapy or after failing such therapy.

\section{Survival analysis and risk factors}

Detailed survival analysis and examination of risk factors for survival was performed on the Mayo cohort, where only $9(3.6 \%)$ of the 248 study patients currently remain alive. Table 3 outlines results of univariate and multivariable analyses of variables collected at time of leukemic transformation. Multivariable analysis of such baseline data identified high risk karyotype, platelet count $<100 \times 10^{9} / \mathrm{L}$, age $>65$ years and red cell transfusion need as independent risk factors for survival; the respective $\mathrm{HR}(95 \% \mathrm{CI})$ were 1.8 (1.3-2.6), 1.5 (1.1-2.1), 1.6 (1.2-2.2), and 1.6 (1.1-2.2). In addition, both age and platelet count remained significant when analyzed as continuous variables and karyotype classified simply as normal vs abnormal (data not shown). Noteworthy in their lack of survival effect included antecedent MPN type and WHO morphological category (data not shown).
Next, we analyzed the effect of specific treatment strategies and response categories on survival. One-year/3-year/ 5 -year survival rates were $66 / 32 / 10 \%$ for patients receiving AlloSCT $(n=24), 37 / 19 / 13 \%$ for patients achieving CR/CRi but were not transplanted $(n=24)$, and $8 / 1 / 1 \%$ in the absence of both AlloSCT and CR/CRi $(n=200)$ $(p<0.01$; Fig. 2a); HR (95\% CI) were $0.2(0.1-0.3)$ for transplant vs no transplant/no CR/CRi; $0.3(0.2-0.5)$ for $\mathrm{CR} / \mathrm{CRi}$ without transplant vs no transplant/no CR/CRi; 0.6 (0.3-1.1) for transplant vs CR/CRi without transplant. In other words, while the survival advantage of transplant over no transplant and that of $\mathrm{CR} / \mathrm{CRi}$ over non-transplanted patients not achieving CR/CRi was confirmed, we were not able to demonstrate a statistically significant difference in survival between patients receiving AlloSCT and those that were not transplanted but had achieved CR/CRi $(p=0.11)$ (Fig. 2a); the latter displayed a median response duration of 3 months (range 0.5 months to 56 months). These observations were in line with the superior survival seen with $\mathrm{CR} / \mathrm{CRi}$ vs no response, among patients receiving intensive induction chemotherapy (Fig. 3a; $p<0.001$ ); on the other hand, survival was similar between patients achieving CR vs CRi (Fig. 3a). Furthermore, among the 24 transplanted patients in the Mayo cohort, outcome was similar whether 

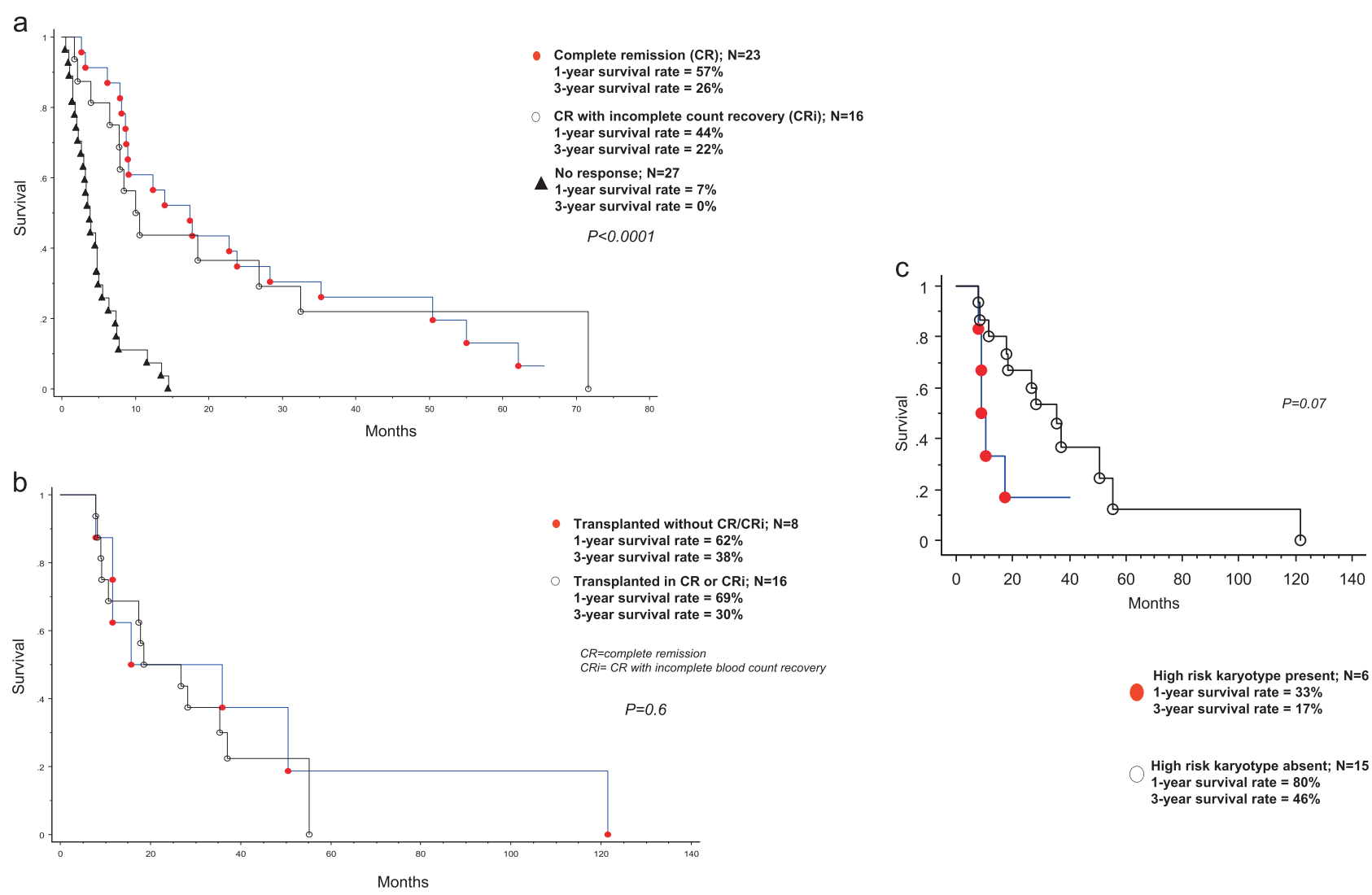

Fig. 3 a Survival data on 66 Mayo Clinic patients with blast-phase myeloproliferative neoplasm, treated with intensive induction chemotherapy and stratified by specific response categories; b Survival data on 24 Mayo Clinic patients with blast-phase myeloproliferative neoplasm, treated with allogeneic stem cell transplantation and

stratified by specific response category at time of transplant; c Survival data on 21 Mayo Clinic patients with blast-phase myeloproliferative neoplasm who were transplanted and stratified by the presence or absence of high risk karyotype

or not $\mathrm{CR} / \mathrm{CRi}$ was documented at time of transplant (Fig. $3 b ; p=0.6$ ). Overall survival in patients receiving HMA was similar to those receiving other form of chemotherapy, in the absence of CR/CRi $(p=0.22)$; in both instances, survival was longer than that seen with supportive care only $(p<0.01)$, but the latter group of patients were significantly older and presumably suffered from poor performance status that contributed to treatment selection.

Finally, we examined the prognostic interaction between baseline risk factors at time of leukemic transformation (i.e., high risk karyotype, thrombocytopenia, advanced age and red cell transfusion need) and specific treatment groups stratified by response categories (i.e., AlloSCT, CR/CRi without AlloSCT, no transplant/no CR/CRi), in a multivariable analysis, and confirmed the inter-independent survival impact of AlloSCT (HR 0.2, 95\% CI 0.1-0.3), CR/CRi without AlloSCT (HR 0.3, 95\% CI 0.2-0.5), high risk karyotype (HR 1.6, 95\% CI 1.1-2.2) and platelet count $<100 \times 10^{9} / \mathrm{L}($ HR $1.6,95 \%$ CI 1.1-2.2). Furthermore, we were intrigued by the possibility that the presence of high risk karyotype might diminish the value of AlloSCT, although the difference in survival did not reach significance (Fig. 3c). The favorable survival impact of transplant and CR/CRi was also suggested in the Italian patient cohort (Fig. 2b).

\section{Discussion}

The current study confirms the dismal prognosis associated with MPN-BP, identifies parameters of success for shortterm survival and highlights the limited value of current therapy, including AlloSCT, in securing long-term survival. We were particularly dismayed with the overall 3-year survival rate of only $6-11 \%$, confirmed in two independent patient cohorts; furthermore, the situation has not improved over the last 15 years, despite the increasing use of more aggressive treatment approaches, including AML-like induction chemotherapy and AlloSCT. A number of practically important observations from the current study deserve bulleted reiteration; (i) it is highly unlikely for nontransplant patients managed with supportive care only, or who do not respond to chemotherapy, to survive for more than 3 years, and more than $90 \%$ might succumb to their 
disease within one year of leukemic transformation; (ii) at present, AML-like induction chemotherapy is the only treatment modality, other than AlloSCT, with the potential to induce $\mathrm{CR}$ or $\mathrm{CRi}$, which appears to be a pre-requisite for improved short-term survival; in this regard, the current study suggests that the likelihood of attaining CR/CRi is not undermined by the presence of high risk karyotype, WHO morphological category or advanced age; (iii) AlloSCT appears to have an age-independent value in prolonging short-term survival; however, the current study raises doubt on the durability of this benefit, beyond 3 years. Furthermore, additional studies are required to clarify the value of pre-transplant induction chemotherapy, which did not appear to modify overall outcome in the current study. It is possible that other factors, such as karyotype, might be more informative, in this regard (Fig. 3c). The latter observation also raises the concern regarding the value of AlloSCT in cytogenetically high risk patients with MPN, who have not yet transformed into MPN-BP.

The overall experience in the current study is consistent with the consensus impression from multiple other reports, which we have summarized in supplemental Table 1, along with the relevant reference list. Conservative approaches, such as the use of HMAs, have had limited value, including a near zero percent chance of achieving CR or CRi and median response durations of less than one year, which might have been a little longer in responders. The salutary effect of AlloSCT has long been suspected and repeatedly demonstrated by previous studies as well (Supplemental Table 1). However, many of the relevant studies in this regard suffer from short follow-up, and observations that are contrary to our own, including the value of attaining CR before transplant; [33-35] for example, a retrospective study in MPN-BP, using the national registry database of the Japan Society for Hematopoietic Cell Transplantation, reported a 2-year post-AlloSCT survival rate of $29 \%$, despite the fact that $82 \%$ of the patients were not in remission at the time of transplant [36]. Regardless, we would like to emphasize the fact that the number of informative cases concerning the use of AlloSCT, in the current study, is simply too small to allow definitive conclusions to be made. The issue is further confounded by the retrospective nature of the study and the absence of uniformity in patient selection and pre-transplant treatment approaches. The issues at hand are more likely to be resolved in the context of prospective clinical trials of AlloSCT in MPNBP. Other limitations of the current study stem from its retrospective design and the incomplete set of available information; for example cytogenetic information was available in only $69 \%$ of the patients in the Mayo cohort, which was a major deterrent from fully appreciating its effect on transplant outcome.
A number of investigational studies are actively addressing the current dire situation with MPN-BP; in one study of 100 patients with myelofibrosis previously exposed to JAK1/2 inhibitor therapy, the outcome of 13 patients transplanted during MPN-BP was not necessarily better than expected, with a 2-year survival of $32 \%$ [37]. Similarly, the JAK1/2 inhibitor ruxolutinib had limited value during a phase- 2 study that included 18 patients with MPNBP [38]. Other agents of interest in MPN-BP include bromo-domain and extra-terminal domain inhibitors (BETi), CPX-351, which is a liposome formulation of cytarabine and daunorubicin, targeted therapy against IDH (enasidenib), CD33 (gemtuzumab ozogomycin) or BCL-2 (venetoclax) [39, 40]. Time will tell whether or not these new drugs will ultimately make a difference in the outcome of MPN-BP. In the meantime, the situation is best addressed by not delaying AlloSCT in MPN patients who are at risk for premature death or leukemic transformation [16].

Acknowledgements Italian researchers were supported by a grant from Associazione Italiana per la Ricerca sul Cancro (AIRC; Milan, Italy), Special Program Molecular Clinical Oncology $5 \times 1000$ to AIRC-Gruppo Italiano Malattie Mieloproliferative (AGIMM) project \#1005). Supported also by a Progetto Ministero della Salute GR-201102352109 to PG. FP was also supported by Fondazione Matarelli, (Milano), Fondazione Rusconi and AIL (Varese). Mayo Clinic funding provided by the Henry J. Predolin foundation grant (Madison, WI, USA).

Author contributions $\mathrm{CAH}$ reviewed pathology data. RPK reviewed cytogenetic data. KHB, MSP, NG, VD, FP, VR, MCF, AR, AB, PG, $\mathrm{AP}$, and AMV contributed patients and assisted in data extraction. FM contributed patients, assisted in data extraction and analysis and preparation of figures. MM assisted in data extraction, analysis and preparation of tables. MY assisted in literature review and preparation of tables. AT developed the study concept and design, contributed patients, assisted in data extraction, performed statistical analysis and wrote the paper.

\section{Compliance with ethical standards}

Conflict of interest The authors declare that they have no conflict of interest.

Open Access This article is licensed under a Creative Commons Attribution-NonCommercial-NoDerivatives 4.0 International License, which permits any non-commercial use, sharing, distribution and reproduction in any medium or format, as long as you give appropriate credit to the original author(s) and the source, and provide a link to the Creative Commons license. You do not have permission under this license to share adapted material derived from this article or parts of it. The images or other third party material in this article are included in the article's Creative Commons license, unless indicated otherwise in a credit line to the material. If material is not included in the article's Creative Commons license and your intended use is not permitted by statutory regulation or exceeds the permitted use, you will need to obtain permission directly from the copyright holder. To view a copy of this license, visit http://creativecommons.org/licenses/by-nc-nd/4.0/. 


\section{References}

1. Swerdlow SH, Campo E, Harris NL, Jaffe ES, Pileri SA, Stein H, et al. WHO classification of tumours of haematopoietic and lymphoid tissues. Lyon, France: IARC; 2017.

2. Barosi G, Mesa RA, Thiele J, Cervantes F, Campbell PJ, Verstovsek S, et al. Proposed criteria for the diagnosis of postpolycythemia vera and post-essential thrombocythemia myelofibrosis: a consensus statement from the International Working Group for Myelofibrosis Research and Treatment. Leukemia. 2008;22:437-38.

3. Tefferi A, Guglielmelli P, Larson DR, Finke C, Wassie EA, Pieri $\mathrm{L}$, et al. Long-term survival and blast transformation in molecularly annotated essential thrombocythemia, polycythemia vera, and myelofibrosis. Blood. 2014;124:2507-13.

4. Barbui T, Thiele J, Passamonti F, Rumi E, Boveri E, Ruggeri M, et al. Survival and disease progression in essential thrombocythemia are significantly influenced by accurate morphologic diagnosis: an international study. J Clin Oncol. 2011;29:3179-84.

5. Cervantes F, Tassies D, Salgado C, Rovira M, Pereira A, Rozman C. Acute transformation in nonleukemic chronic myeloproliferative disorders: actuarial probability and main characteristics in a series of 218 patients. Acta Haematol. 1991;85:124-7.

6. Tefferi A, Rumi E, Finazzi G, Gisslinger H, Vannucchi AM, Rodeghiero F, et al. Survival and prognosis among 1545 patients with contemporary polycythemia vera: an international study. Leukemia. 2013;27:1874-81.

7. Mesa RA, Li CY, Ketterling RP, Schroeder GS, Knudson RA, Tefferi A. Leukemic transformation in myelofibrosis with myeloid metaplasia: a single-institution experience with 91 cases. Blood. 2005;105:973-7.

8. Tam CS, Nussenzveig RM, Popat U, Bueso-Ramos CE, Thomas DA, Cortes JA, et al. The natural history and treatment outcome of blast phase BCR-ABL-myeloproliferative neoplasms. Blood. 2008;112:1628-37.

9. Passamonti F, Rumi E, Arcaini L, Castagnola C, Lunghi M, Bernasconi $\mathrm{P}$, et al. Leukemic transformation of polycythemia vera: a single center study of 23 patients. Cancer. 2005;104:1032-6.

10. Huang J, Li CY, Mesa RA, Wu W, Hanson CA, Pardanani A, et al. Risk factors for leukemic transformation in patients with primary myelofibrosis. Cancer. 2008;112:2726-32.

11. Dupriez B, Morel P, Demory JL, Lai JL, Simon M, Plantier I, et al. Prognostic factors in agnogenic myeloid metaplasia: a report on 195 cases with a new scoring system. Blood. 1996;88:1013-8.

12. Passamonti F, Rumi E, Elena C, Arcaini L, Merli M, Pascutto C, et al. Incidence of leukaemia in patients with primary myelofibrosis and RBC-transfusion-dependence. $\mathrm{Br} \mathrm{J}$ Haematol. 2010;150:719-21.

13. Tefferi A, Vaidya R, Caramazza D, Finke C, Lasho T, Pardanani A. Circulating interleukin (IL)-8, IL-2R, IL-12, and IL-15 levels are independently prognostic in primary myelofibrosis: a comprehensive cytokine profiling study. J Clin Oncol. 2011;29:1356-63.

14. Barbui T, Carobbio A, Finazzi G, Guglielmelli P, Salmoiraghi S, Rosti V, et al. Elevated C-reactive protein is associated with shortened leukemia-free survival in patients with myelofibrosis. Leukemia. 2013;27:2084-6.

15. Vaidya R, Caramazza D, Begna KH, Gangat N, Van Dyke DL, Hanson CA, et al. Monosomal karyotype in primary myelofibrosis is detrimental to both overall and leukemia-free survival. Blood. 2011;117:5612-5.

16. Vannucchi AM, Lasho TL, Guglielmelli P, Biamonte F, Pardanani A, Pereira A, et al. Mutations and prognosis in primary myelofibrosis. Leukemia. 2013;27:1861-9.
17. Tefferi A, Guglielmelli P, Lasho TL, Rotunno G, Finke C, Mannarelli C, et al. CALR and ASXL1 mutations-based molecular prognostication in primary myelofibrosis: an international study of 570 patients. Leukemia. 2014;28:1494-500.

18. Tefferi A, Lasho T, Finke C, Elala Y, Hanson C, Ketterling R, et al. Targeted deep sequencing in primary myelofibrosis. Blood Adv. 2016;1:105-11.

19. Tefferi A, Lasho TL, Abdel-Wahab O, Guglielmelli P, Patel J, Caramazza D, et al. IDH1 and IDH2 mutation studies in 1473 patients with chronic-, fibrotic- or blast-phase essential thrombocythemia, polycythemia vera or myelofibrosis. Leukemia. 2010;24:1302-9.

20. Pardanani A, Lasho TL, Finke CM, Mai M, McClure RF, Tefferi A. IDH1 and IDH2 mutation analysis in chronic- and blast-phase myeloproliferative neoplasms. Leukemia. 2010;24:1146-51.

21. Berk PD, Wasserman LR, Fruchtman SM, Goldberg JD. Treatment of polycythemia vera: a summary of clinical trials conducted by the Polycythemia Vera Study Group. In: Wasserman LR, Berk PD, Berlin NI, eds. Polycythemia vera and the myeloproliferative disorders. Philadelphia: WB Saunders; 1995. p. 166-94.

22. Finazzi G, Caruso V, Marchioli R, Capnist G, Chisesi T, Finelli C, et al. Acute leukemia in polycythemia vera: an analysis of 1638 patients enrolled in a prospective observational study. Blood. 2005; 105:2664-70.

23. Marchioli R, Finazzi G, Landolfi R, Kutti J, Gisslinger H, Patrono $\mathrm{C}$, et al. Vascular and neoplastic risk in a large cohort of patients with polycythemia vera. J Clin Oncol. 2005;23:2224-32.

24. Gangat N, Strand J, Li CY, Wu W, Pardanani A, Tefferi A. Leucocytosis in polycythaemia vera predicts both inferior survival and leukaemic transformation. Br J Haematol. 2007;138:354-8.

25. Tefferi A, Lasho TL, Guglielmelli P, Finke CM, Rotunno G, Elala $\mathrm{Y}$, et al. Targeted deep sequencing in polycythemia vera and essential thrombocythemia. Blood Adv. 2016;1:21-30.

26. Gangat N, Wolanskyj AP, McClure RF, Li CY, Schwager S, Wu $\mathrm{W}$, et al. Risk stratification for survival and leukemic transformation in essential thrombocythemia: a single institutional study of 605 patients. Leukemia. 2007;21:270-6.

27. Chim CS, Kwong YL, Lie AK, Ma SK, Chan CC, Wong LG, et al. Long-term outcome of 231 patients with essential thrombocythemia: prognostic factors for thrombosis, bleeding, myelofibrosis, and leukemia. Arch Intern Med. 2005;165:2651-8.

28. Abdulkarim K, Ridell B, Johansson P, Kutti J, Safai-Kutti S, Andreasson B. The impact of peripheral blood values and bone marrow findings on prognosis for patients with essential thrombocythemia and polycythemia vera. Eur J Haematol. 2011;86:148-55.

29. Tefferi A, Gangat N, Wolanskyj AP, Schwager S, Pardanani A, Lasho TL, et al. $20+$ yr without leukemic or fibrotic transformation in essential thrombocythemia or polycythemia vera: predictors at diagnosis. Eur J Haematol. 2008;80:386-90.

30. Passamonti F, Rumi E, Arcaini L, Boveri E, Elena C, Pietra D, et al. Prognostic factors for thrombosis, myelofibrosis, and leukemia in essential thrombocythemia: a study of 605 patients. Haematologica. 2008;93:1645-51.

31. Yogarajah M, Tefferi A. Leukemic transformation in myeloproliferative neoplasms: a literature review on risk, characteristics, and outcome. Mayo Clin Proc. 2017;92:1118-28.

32. Tefferi A, Jimma T, Gangat N, Vaidya R, Begna KH, Hanson CA, et al. Predictors of greater than $80 \%$ 2-year mortality in primary myelofibrosis: a Mayo Clinic study of 884 karyotypically annotated patients. Blood. 2011;118:4595-8.

33. Alchalby $\mathrm{H}$, Zabelina T, Stubig T, van Biezen A, Bornhauser M, Di Bartolomeo P, et al. Allogeneic stem cell transplantation for myelofibrosis with leukemic transformation: a study from the Myeloproliferative Neoplasm Subcommittee of the CMWP of the 
European Group for Blood and Marrow Transplantation. Biol Blood Marrow Transplant. 2014;20:279-81.

34. Cahu X, Chevallier P, Clavert A, Suarez F, Michallet M, Vincent L, et al. Allo-SCT for Philadelphia-negative myeloproliferative neoplasms in blast phase: a study from the Societe Francaise de Greffe de Moelle et de Therapie Cellulaire (SFGM-TC). Bone Marrow Transplant. 2014;49:756-60.

35. Kennedy JA, Atenafu EG, Messner HA, Craddock KJ, Brandwein $\mathrm{JM}$, Lipton JH, et al. Treatment outcomes following leukemic transformation in Philadelphia-negative myeloproliferative neoplasms. Blood. 2013;121:2725-33.

36. Takagi S, Masuoka K, Uchida N, Kurokawa M, Nakamae H, Imada K, et al. Allogeneic hematopoietic cell transplantation for leukemic transformation preceded by philadelphia chromosomenegative myeloproliferative neoplasms: a nationwide survey by the adult acute myeloid leukemia working group of the Japan Society for Hematopoietic Cell Transplantation. Biol Blood Marrow Transplant. 2016;22:2208-13.
37. Shanavas M, Popat U, Michaelis LC, Fauble V, McLornan D, Klisovic R, et al. Outcomes of allogeneic hematopoietic cell transplantation in patients with myelofibrosis with prior exposure to Janus Kinase 1/2 inhibitors. Biol Blood Marrow Transplant. 2016;22:432-40.

38. Eghtedar A, Verstovsek S, Estrov Z, Burger J, Cortes J, Bivins C, et al. Phase 2 study of the JAK kinase inhibitor ruxolitinib in patients with refractory leukemias, including postmyeloproliferative neoplasm acute myeloid leukemia. Blood. 2012;119:4614-8.

39. Saenz DT, Fiskus W, Manshouri T, Rajapakshe K, Krieger S, Sun $\mathrm{B}$, et al. BET protein bromodomain inhibitor-based combinations are highly active against post-myeloproliferative neoplasm secondary AML cells. Leukemia. 2017;31:678-87.

40. Wei AH, Tiong IS. Midostaurin, enasidenib, CPX-351, gemtuzumab ozogomycin and venetoclax bring new hope to AML. Blood. 2017. 